\title{
ARQUEOLOGÍA DE LAS OCUPACIONES \\ CAZADORAS-RECOLECTORAS DE FINES DEL HOLOCENO MEDIO DE ANTOFAGASTA DE LA SIERRA (PUNA MERIDIONAL ARGENTINA)*
}

\author{
ARCHAEOLOGY OF LATE MIDDLE HOLOCENE HUNTER-GATHERERS \\ OF ANTOFAGASTA DE LA SIERRA (SOUTHERN ARGENTINEAN PUNA)
}

\author{
Carlos Alberto Aschero ${ }^{1}$ y Salomón Hocsman ${ }^{1}$
}

\begin{abstract}
Se presenta una caracterización de las ocupaciones cazadoras-recolectoras del lapso ca. 5.500-3.000 años a.p. en Antofagasta de la Sierra (Puna Meridional argentina), a través de diferentes líneas de evidencia: confección de tecnofacturas, arte rupestre, movilidad residencial, territorialidad, explotación de recursos animales y vegetales silvestres y domesticados y obtención de recursos bióticos y abióticos procedentes de grandes distancias. Cabe destacar que en este lapso se producen en el área importantes cambios socioeconómicos relacionados con la puesta en práctica de actividades productivas. Al respecto, se sostiene que tales cambios se produjeron en el seno de los grupos cazadores-recolectores locales y en la suma de interacciones con grupos de subsistencia semejantes, y que no se debieron a estímulos transformadores desde "áreas nucleares". Asimismo, se analiza la porción estudiada de la secuencia arqueológica local en comparación con información generada para la Puna Septentrional argentina y el desierto del norte de Chile. Esto tiene por objeto abordar la variabilidad de los procesos en las distintas áreas de investigación, así como posibles relaciones entre los mismos.
\end{abstract}

Palabras claves: cazadores-recolectores, inicio de actividades productivas, Holoceno Medio/Tardío, Puna argentina.

A characterization of last hunter-gatherer occupations at Antofagasta de la Sierra (Southern Argentinean Puna) is presented (ca. 5,500-3,000 years BP). Different lines of evidence are considered: technofactures, rock art, residential mobility, territoriality, wild and domesticated animal and plant resources exploitation and non local biotic and abiotic resource procurement. It is highlighted that at this moment important socio-economic changes related to the emergence of productive activities occurred in the study area. We consider that such changes took place inside of local hunter-gatherer groups and from the sum of interactions with similar subsistence groups and that they were not owed to transformer stimulus from "nuclear areas". Besides, the local archaeological sequence studied is compared to contemporaneous information from Northern Argentinean Puna and desert of Chile. The goal is to board the variability in processes from different areas and possible relationships within them.

Key words: Hunter-gatherers, initial productive activities, Middle/Late Holocene, Argentinean Puna.

Antofagasta de la Sierra, situada en la Puna Meridional argentina, cuenta con una vasta y prolífica trayectoria en el estudio de los grupos cazadores-recolectores holocénicos (Aschero 1999; Aschero et al. 1991; Aschero et al. 1993-94; Manzi 2006; Martínez 2003; Pintar 1996, 2004; entre otros) y ha sido y es una de las principales fuentes de información en el Noroeste Argentino en cuanto al cambio de la subsistencia de dichos cazadoresrecolectores a un modo de vida agropastoril.

Los resultados obtenidos, desde un caso arqueológico específico, aportan a la discusión de diversos aspectos de interés para la antropología y arqueología contemporáneas interesadas en el estudio de los grupos cazadores-recolectores, referidos a los alcances (y límites) de la noción de cazador-recolector, la variabilidad involucrada en esta categoría y la diversidad de situaciones en los procesos de cambio socioeconómico a la producción de alimentos (Barnard 2004; Bodley 1999; Harris y Hillman 1989; Kelly 1995; Lee y Daly 1999; PanterBrick et al. 2001; Price y Gebauer 1995; Stiles 2001; Svelebil 2009; Whittle y Cummings 2007).

* Un texto preliminar de este artículo fue presentado en el $53^{\circ}$ Congreso Internacional de Americanistas, Simposio "El período Arcaico en los Andes Sur Centrales: Tradiciones culturales e innovaciones tecnológicas", Ciudad de México, 19 al 24 de julio de 2009. Este manuscrito fue evaluado por investigadores externos y editado por Luis Flores Blanco y Mark S. Aldenderfer, en su calidad de editores invitados de la Revista.

1 CONICET. Instituto de Arqueología y Museo (IAM), Facultad de Ciencias Naturales e Instituto Miguel Lillo, Universidad Nacional de Tucumán, Instituto Superior de Estudios Sociales (ISES), CONICET-Universidad Nacional de Tucumán. San Martín 1.545 (CP 4.000) San Miguel de Tucumán, Tucumán, Argentina. ascherocarlos@ yahoo.com.ar; shypb@arnet.com.ar 
Como punto de partida, se plantea la continuidad en la transmisión generacional de información y prácticas de hacer a través del tiempo; involucrando, al mismo tiempo, cambios que pueden rastrearse en su origen a las mismas ocupaciones cazadorasrecolectoras (Aschero 1994, 2010; Hocsman 2006), lo cual implica situar al proceso de cambio en el ámbito y las interacciones de la porción meridional de los Andes Centro-Sur (Núñez et al. 2006) y no como un mero reflejo de desarrollos desde "áreas nucleares".

\section{Ambiente y Paleoambiente}

Antofagasta de la Sierra se sitúa en el ángulo noroeste de la provincia de Catamarca y forma parte de la Puna Meridional Argentina (Figura 1). Siguiendo a Troll (1958), se pueden reconocer dentro de la Puna sectores con características ambientales diferentes. En el caso de la Puna Argentina, dichos sectores son la Puna Seca y la Salada o Desértica. La primera se localiza en la porción noroeste y es la zona más húmeda, mientras que la segunda es más seca, conteniendo extensas áreas con salares y salinas, resultado de humedad reducida y altas tasas de evaporación (Olivera 1998; Yacobaccio 1998). Antofagasta de la Sierra se incluye en esta última.

El paisaje del área se caracteriza por la presencia de planicies suavemente onduladas, interrumpidas por afloramientos de rocas ígneas y metamórficas así como cordones volcánicos y secuencias de rocas sedimentarias asociadas (González 1992) (Figura 2). El área cuenta y ha contado en el pasado con una serie de condiciones que la han hecho favorable a la ocupación humana. Tales elementos están dados por sectores con cauces fluviales acotados pero permanentes, asociados a una buena disponibilidad de pasturas y de fauna. A ello se suma una excelente oferta local de materias primas líticas y otros recursos minerales esenciales como sales comestibles y alumbres. Debe destacarse, además, la abundancia de sectores de habitación con reparos naturales conformados por farallones de ignimbritas

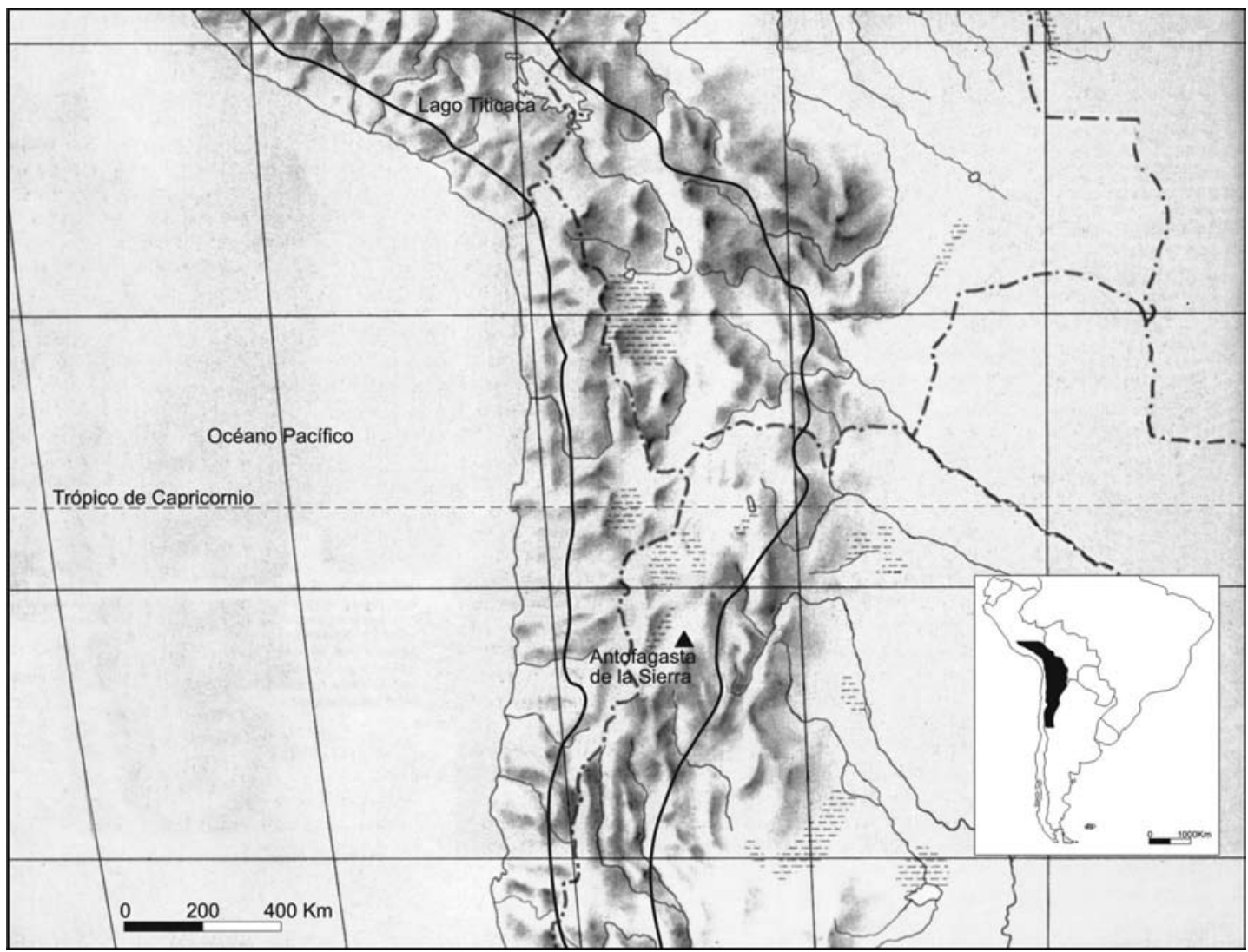

Figura 1. Ubicación de Antofagasta de la Sierra en el contexto del ámbito puneño.

Location of Antofagasta de la Sierra in the Puna region. 


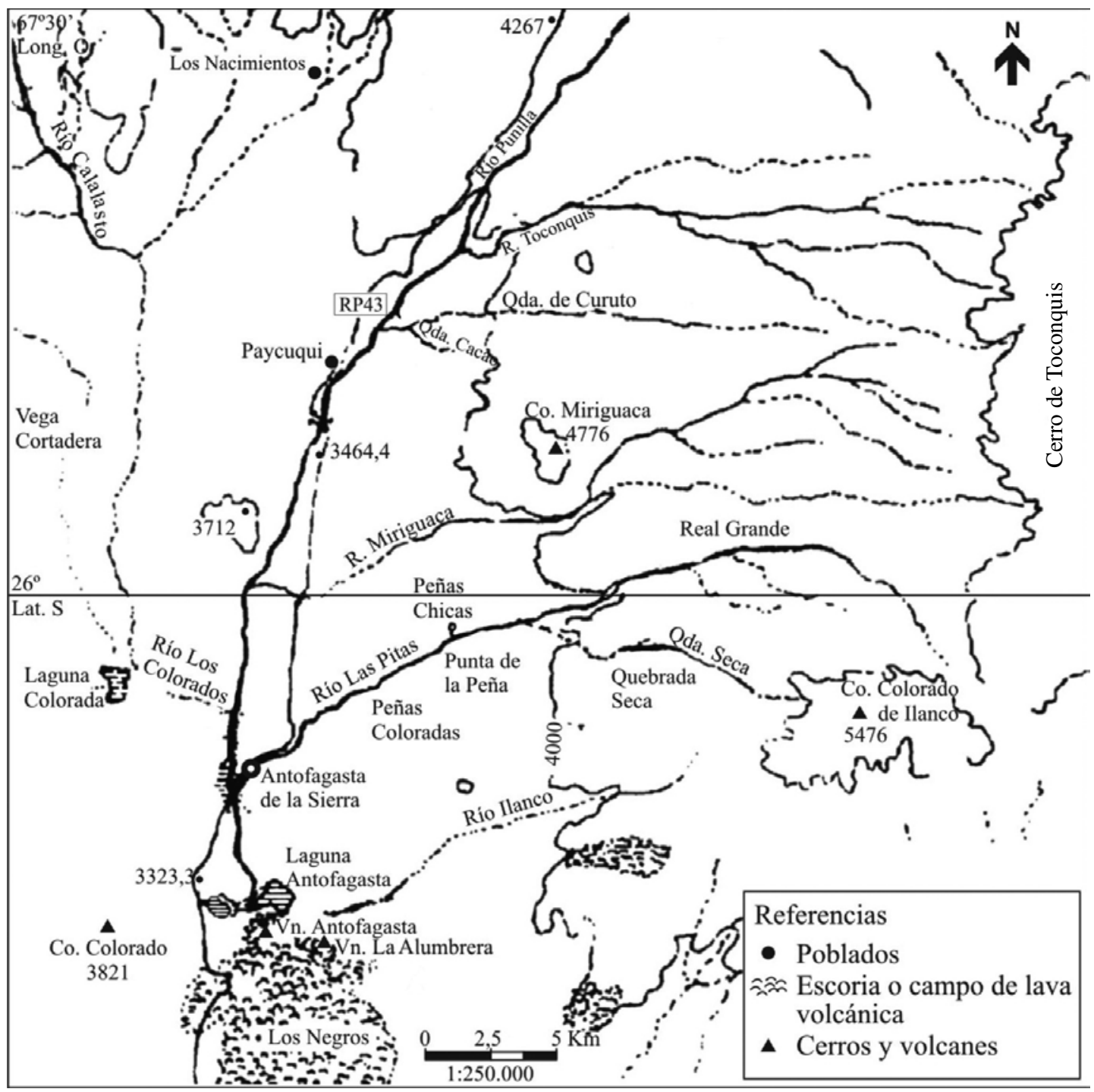

Figura 2. La cuenca del Río Punilla (Antofagasta de la Sierra, Argentina).

Río Punilla Basin (Antofagasta de la Sierra, Argentina).

y sectores de desprendimientos asociados (Aschero et al. 2002-2004). El caso de Antofagasta de la Sierra sería producto del contraste de un ambiente de parche, con múltiples "zonas de concentración de nutrientes" (Yacobaccio 1994) relacionadas a la cuenca del Río Punilla, circundadas por un desierto extremo.

Recientemente, Olivera et al. (2006) han obtenido una secuencia paleoambiental local, generada en base a análisis sedimentológicos, geomorfológicos y pedológicos, así como a análisis isotópicos de ${ }^{18} \mathrm{O}$ y ${ }^{13} \mathrm{C}$, en lagunas, cursos de agua y vegas. De acuerdo a los resultados alcanzados
(Olivera et al. 2006; Tchilinguirian y Olivera 2009), el lapso abordado se vio sometido a una serie de cambios ambientales de magnitud. A partir de los 8.500 años a.p. se produjo un proceso de aridización gradual, notablemente marcado desde los 6.500/6.000 a.p., tornándose árido y cálido. Hacia los 4.500-4.000 años a.p. se registra un período de elevada humedad y de excedente de agua, que finaliza ca. 1.600 a.p. Posteriormente a esta fecha se inicia un nuevo período de aridización que comienza a configurar el ambiente actual.

Es factible sostener que los cambios ambientales, tanto climáticos como geomorfológicos, 
incidieron directamente sobre los humedales, materializándose en expansiones y retracciones y en apariciones-desapariciones. Sin embargo, de esta historia ambiental dinámica de Antofagasta de la Sierra se desprende que dicha área siempre contó con importantes recursos hídricos y humedales aun en momentos de aridez extrema, con la consecuente flora y fauna asociadas.

En relación con esto último, un punto importante a nivel macrorregional para la ocupación humana durante el Holoceno Medio es la concentración de recursos en áreas favorecidas, denominados "ecorrefugios" (Núñez et al. 2001). De esta forma, se han establecido ecorrefugios en la Quebrada de Puripica -norte de Chile- (Núñez et al. 1999) y en la Quebrada de Lapao-Susques, Jujuy-(Yacobaccio y Morales 2005). También se ha considerado a Antofagasta de la Sierra como un ecorrefugio (Núñez et al. 1999), pero hay diferencias de escala espacial y de continuidad temporal de los recursos hídricos que son importantes para no considerar al área como un ecorrefugio. En efecto, la extensión espacial de los recursos hídricos como espejos lacustres o cauces interconectados es mucho mayor que los sectores de las Quebradas de Puripica y Lapao involucrados, implicando un cambio sustancial de escala. En segundo lugar, y más importante aún, Antofagasta de la Sierra siempre contó con recursos hídricos y bióticos mientras que los ecorrefugios propiamente dichos de Puripica y Lapao se caracterizan por ser episódicos.

\section{Evidencias de Cazadores-Recolectores Finales de Antofagasta de la Sierra}

\section{Sitios, emplazamiento y cronología}

Las evidencias de ocupación humana se incrementan notablemente en Antofagasta de la Sierra desde los 4.000 años a.p. aproximadamente, al considerar sólo los sitios con cronología absoluta. Pero no sólo es mayor la cantidad de sitios, sino que también aumenta el número de los mismos con ocupaciones relativamente sincrónicas (Tabla 1).

Los sitios identificados hasta el momento para el lapso 5.500-3.000 a.p. se encuentran entre los 3.500 y los $4.500 \mathrm{msm}$, en una serie de quebradas y vegas con altitudes superiores a los $3.600 \mathrm{msm}$ (localidades arqueológicas de Quebrada Seca, Real Grande, Punta de la Peña, Quebrada Salamanca-El Sembrado, Peñas Chicas, Peñas Coloradas y Cacao-Curuto) y en los sectores más bajos de la microrregión, hacia los 3.500 msm, a saber: Laguna Antofagasta-Río Punilla (localidades arqueológicas de La Torre y Confluencia) y Laguna Colorada (localidad arqueológica del mismo nombre) (Figura 2).

En este momento destaca la diversidad de los sitios en funcionamiento: (a) bases residenciales en reparos rocosos con espacios acondicionados y equipamiento: Quebrada Seca 3 (QS3), Punta de la Peña 4 (PP4), Peñas Chicas 1.3 (PCh1.3-alero bajo roca); (b) bases residenciales en reparos rocosos con espacios acondicionados: Peñas de las Trampas 1.1 (PT1.1), Cueva Salamanca 1 (CS1) y Punta de la Peña 3A (PP3A); (c) bases residenciales en reparos rocosos con equipamiento: Peñas Chicas 1.1 (PCh1.1); (d) bases residenciales a cielo abierto con equipamiento: Peñas Chicas 1.6 (PCh1.6); (e) depósitos intencionales de objetos en aleros bajo roca y abrigos rocosos, en la forma de tumbas $\mathrm{u}$ ofrendas: Punta de la Peña 11A (PP11A), Punta de la Peña 11B (PP11B), Peñas Chicas 1.5 (PCh1.5) y Cacao 1A (Cc1A); (f) sitios con arte rupestre en reparos rocosos y farallones de ignimbrita sin ocupación: Quebrada Seca 1 (QS1), Quebrada Seca 2 (QS2), Real Grande 3 (RG3), Curuto 5 (Cu5), Peñas Coloradas 1 (PC1), Confluencia 1 (C1), Laguna Colorada 1 (LC1) y La Torre 1 (LT1); (g) sitios con arte rupestre y ocupación residencial en reparos rocosos: Cueva Cacao $1 \mathrm{~A}(\mathrm{Cc} 1 \mathrm{~A})$; (h) estaciones de caza por intercepción con parapetos de piedra: Real Grande 11 (RG11) y Laguna Colorada 7 (LC7); (i) estaciones de caza por intercepción con parapetos de piedra y arte rupestre: Laguna Colorada 3 (LC3); y (j) canteras y canteras-taller: Quebrada Seca Zona de Aprovisionamiento y Cantera, Pampa Oeste, y Punta de la Peña Zona de Aprovisionamiento y Cantera, entre otras. Los yacimientos listados cuentan con cronología absoluta (Tabla 1) o bien tienen una adscripción cronológica en función de la presencia de artefactos temporalmente sensibles, de la vinculación entre motivos rupestres y contextos datados y/o del análisis de superposiciones en el arte rupestre. Las bases residenciales se presentan mayoritariamente en aleros y cuevas, con superficies reparadas que van de los 16 a los $200 \mathrm{~m}^{2}$. La excepción la constituye PCh1.6, un sitio a cielo abierto con una extensión en superficie de $7.500 \mathrm{~m}^{2}$ y materiales en estratigrafía. El patrón de asentamiento se caracterizaría por bases residenciales dispersas a nivel microrregional, pero algunas de ellas muy cercanas entre sí. Es el caso de los sitios PCh1.3, PCh1.1, PCh1.6 y PP4, con 


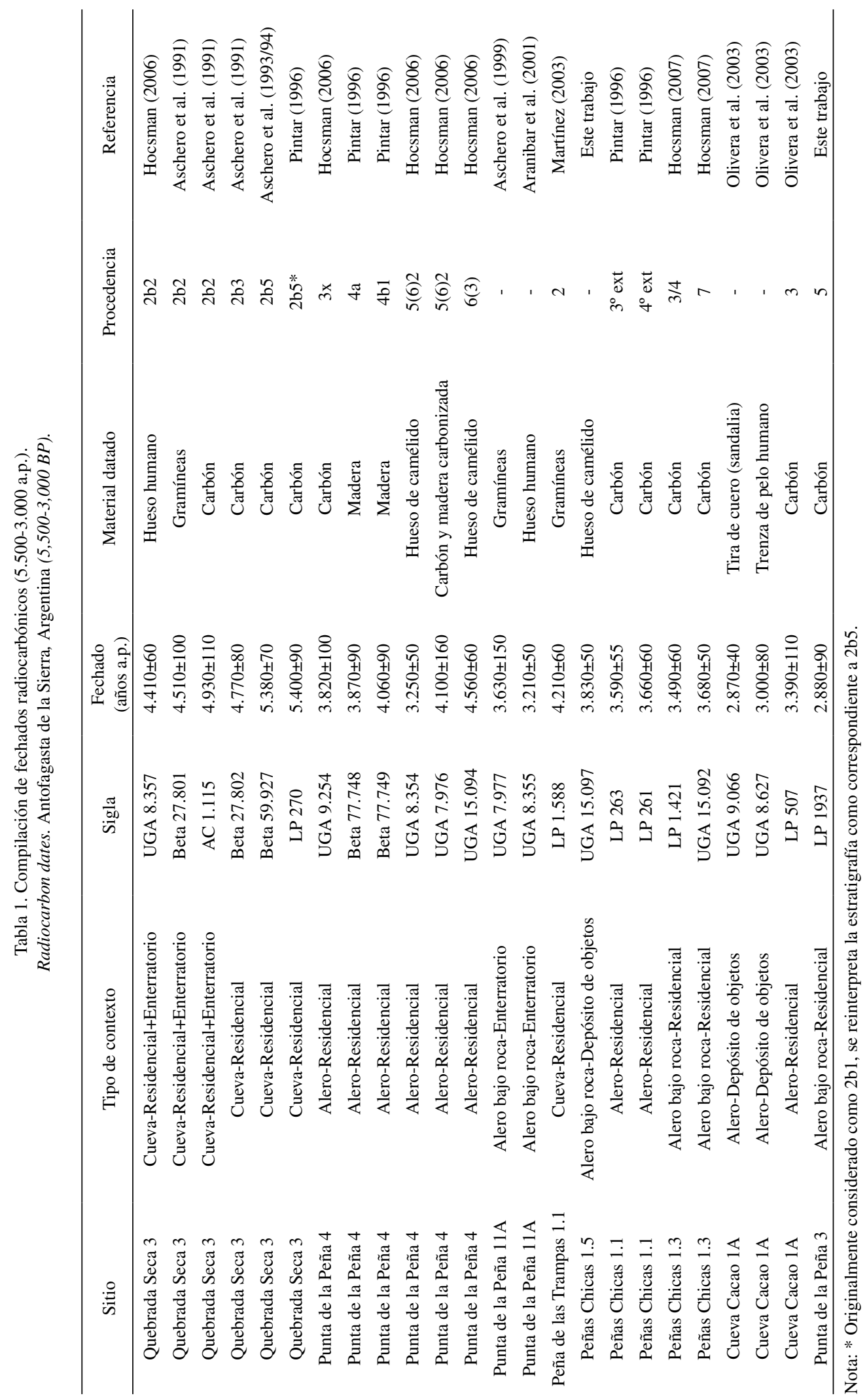


cronología hacia los 3.500 a.p. y distancias entre sí menores a $700 \mathrm{~m}$.

Pese a que la mayoría de los sitios residenciales se presenta en reparos rocosos, se evidencia una diversificación de los mismos, ya que presentan espacios acondicionados y/o equipamiento de sitio. A partir de los 5.500 a.p. se registran cambios en la organización del espacio. Así, por ejemplo, en los niveles $2 \mathrm{~b} 5$ a $2 \mathrm{~b} 2$ de QS3 se observa un emplazamiento diferente de los fogones y de las dispersiones de tecnofacturas y ecofactos, a lo que se suman posibles estructuras de cavado en $2 \mathrm{~b} 3$, ya sea que se trate de relictos de pozos de almacenamiento o lugares preparados para asiento (Aschero et al. 199394). Tales espacios acondicionados se encuentran también en otros sitios en forma de estructuras de piedra adosadas, con cronologías absolutas entre 4.000 y 3.500 años a.p. Un ejemplo de esto es el sitio PP4 con cuatro estructuras circulares parcialmente desarmadas construidas contra la pared del alero, que no pueden adscribirse a corrales. Los bloques que conforman la base de las mismas apoyan inmediatamente bajo el nivel 5(2) e incluyen el nivel 5(1) suprayacente. Responde a estas características también PCh1.3, ya que el alero bajo roca cuenta con una estructura de piedra en parte desarmada bajo la línea de goteo del abrigo. Finalmente, Cueva Salamanca 1, que posee tres estructuras pircadas. El hallazgo de una punta lanceolada pequeña en una sugeriría su uso ca. 3.500 a.p. de acuerdo a Pintar (2004).

Es pertinente denotar que en Antofagasta de la Sierra no se cuenta aún con estructuras de recintos aglomerados complejos a cielo abierto, con fechas entre 4.800 y 3.200 a.p., como sí ocurre en el Desierto de Atacama (Chile) con los sitios Tulán 52, Puripica 1 y Tulán 54 (Núñez 1992; Núñez et al. 2006). Sitios residenciales de planta subcircular están presentes en el área recién con grupos agropastoriles plenos, fechados al comienzo de la era (Babot et al. 2006; Olivera 1992).

Destacan, finalmente, una serie de hallazgos, en forma de "ofrendas" y/o enterratorios, caracterizados por ser eventos discretos de depositación en abrigos rocosos u oquedades, en asociación con fuentes de agua y vegetación abundante (Olivera et al. 2003). A esto se suma, en igual cronología, un culto a la fertilidad de los camélidos silvestres y domésticos (Aschero 2007), en el que el sitio Confluencia 1 habría tenido un papel simbólico-ritual.

\section{Movilidad residencial reducida y territorialidad}

Distintas evidencias permiten sostener una situación de disminución de la movilidad residencial en relación con momentos previos de la secuencia arqueológica abordada. La ocurrencia de movilidad residencial reducida implica cambios en el patrón de asentamiento (mayor tamaño, duración y diferenciación), tanto en organización interna como en el número y variedad de sitios (Kelly 1992; Rafferty 1985). Al respecto, la información aportada en el punto anterior da cuenta de una diversificación en la utilización del espacio al interior de los sitios y de una importante variedad de sitios que cumple con las expectativas enunciadas.

La presencia de recintos habitacionales es uno de los indicadores arqueológicos más comúnmente usado en la identificación de movilidad reducida/ sedentarismo (Kelly 1992); aunque, siguiendo a Aldenderfer (1998), contar con estructuras habitacionales no es garantía de que la ocupación haya sido sedentaria. No obstante, la recurrencia del hallazgo de estructuras de piedra en los sitios residenciales con cronología entre los 4.000 y los 3.000 años a.p. está señalando una situación particular relacionada con nuevas formas de concebir el espacio.

Otras evidencias se refieren a las distancias de búsqueda de recursos explotados. Así, en relación con la recolección de especies leñosas y herbáceas utilizadas -como leña, para el revestimiento de pisos de ocupación (Deyeuxia eminens) o para cestería (Cortaderia sp.)-, las evidencias sugieren distancias entre 0 y $20 \mathrm{~km}$ desde sitios ubicados en Quebrada Seca, Punta de la Peña o Peñas Chicas (Aguirre 2005; Rodríguez 1999, 2004).

Respecto a las rocas utilizadas en la producción de artefactos líticos tallados, de las 17 variedades utilizadas, 11 de ellas fueron obtenidas en fuentes distribuidas en un radio no mayor a $15 \mathrm{~km}$, tomando como centro la localidad de Punta de la Peña, por lo que la prueba y selección de las variedades de rocas se realizó en espacios próximos a los asentamientos, significando una movilidad restringida entre espacios con recursos líticos conocidos (Aschero et al. 2002-2004).

Por otra parte, la creciente fijación de los grupos humanos al paisaje a escala micro no incidió en una disminución de la circulación regional (macromovilidad). La información sustenta ambas situaciones: una micromovilidad reducida y una 
macromovilidad en pleno funcionamiento (Hocsman 2002, 2006). Es decir, que son las materias primas locales las indicadas para tratar variaciones en la movilidad residencial microrregional (Hocsman 2006, 2009).

Para el abordaje de las variaciones en el tiempo de la representatividad de las rocas locales se utiliza la diferenciación de Hocsman (2009) en inmediatas (aquellas que se encuentran a una distancia menor o igual a $2 \mathrm{~km}$ ), mediatas cercanas (localizadas entre 2 y $10 \mathrm{~km}$ ), mediatas lejanas (situadas a más de $10 \mathrm{~km}$ y a menos de $25 \mathrm{~km}$ ) y no diferenciadas (rocas en las que se puede establecer su carácter local pero en las que no es posible discernir si se trata de inmediatas o mediatas). El análisis de las frecuencias de las distintas clases de materias primas locales, tomando como caso los instrumentos tallados, revela un marcado incremento en el uso de las rocas inmediatas entre los 5.500-4.500 a.p. y $3.800-3.400$ a.p., de $53,77 \%$ a $75,83 \%$ y, como correlato, una disminución del papel de las mediatas, tomadas en conjunto, de 42,46\% a 21,53\%. Asimismo, disminuyen los dos tipos de rocas mediatas al pasar de un momento a otro, aunque las rocas mediatas lejanas tienen la particularidad de que se reducen a una mínima expresión ca. 3.600 a.p., siendo del $1,99 \%$. Puede postularse, entonces, una progresiva restricción en la movilidad residencial (y logística), al haber una cada vez menor representación de rocas de más de $2 \mathrm{~km}$ y menos de $25 \mathrm{~km}$ y, al mismo tiempo, un recorte en las distancias de aprovisionamiento.

Otro aspecto relevante es la duración de las ocupaciones. En general, los datos disponibles dan cuenta de permanencia durante los meses de primavera-verano y comienzos del otoño en QS3 y PCh1.3, por ejemplo, de acuerdo a la presencia de camélidos recién nacidos en el registro arqueofaunístico en el primer caso y de frutos y/o flores en ambos casos (Aguirre 2005; Rodríguez y Rúgolo de Agrasar 1999). Sin embargo, información reciente daría cuenta de ocupaciones más prolongadas, tanto en estos sitios como en otros (PCh1.1 y PP4), ya que se han recuperado cultígenos como microrrestos en artefactos de molienda-Chenopodium sp. aff. C. quinoa, Solanum tuberosum, Oxalis tuberosa, entre otros- (Babot 2004, 2005) que, al vincularse con el hallazgo de macrorrestos de tallo de una quenopodiácea doméstica en PCh1.3 (Aguirre 2007, 2009), implicarían la ocurrencia local de actividades de siembra y cosecha.
Al extrapolar datos de Muscio (2004) referidos a San Antonio de los Cobres (Puna de Salta) -distante a aproximadamente $300 \mathrm{~km}$ en línea recta de Antofagasta de la Sierra-, la época de siembra para estos recursos es septiembre-octubre y la de cosecha marzo-abril. Esto implicaría que habría habido estadías de seis meses, como mínimo, entre la siembra y la cosecha, vinculadas al cuidado de los cultivos, ya sea de parte del grupo o del grupo completo (Hocsman 2007). Si bien es cierto que dicho cuidado puede no ser una actividad diaria y que no conlleva necesariamente a una situación de residencia permanente en los sitios residenciales cercanos, de todas formas está dando cuenta de usos más intensivos de sectores del espacio en momentos relativamente extensos del año, que seguramente afectaron la movilidad residencial.

Cabe destacar que se ha sugerido para el lapso considerado una movilidad muy pautada, con retorno a lugares previstos, en el marco de un sistema de asentamiento semisedentario o bien de recorridos/ circuitos estacionales bien demarcados (Aschero 1999; Aschero et al. 1993-94). La presencia de artefactos de molienda descartados como "residuos de facto" en QS3, PP4, PCh1.1 y PCh1.3, más las características morfológicas de los mismos, señalan también la posibilidad de ocupaciones redundantes, recurrentes y anticipadas en los mismos (Babot 2006, 2009). La ocurrencia de cultivos no sólo estaría en correspondencia con esto, sino que permitiría avizorar una situación de mayor sedentarismo de la que previamente se había considerado.

Es pertinente señalar que las características ambientales existentes a partir del Holoceno Medio en la Puna Argentina, definidas por un ambiente en mosaico, podrían haber generado un terreno propicio para la circunscripción social. Este pudo ser el caso de Antofagasta de la Sierra, ya que el área contaba con recursos hídricos y vegetales importantes en relación a las condiciones imperantes en el resto de la Puna Salada. La situación de circunscripción social en este caso estaría definida por barreras ambientales, con distintas zonas de concentración de nutrientes relacionadas a la cuenca del Río Punilla y éstas, a su vez, circundadas por un desierto extremo. La circunscripción estaría generada por la competencia social entre estos territorios con muy baja productividad primaria, que llevaría a una demarcación más estricta de los mismos. Aschero (2009) señala que el arte rupestre en Antofagasta de la Sierra se asocia a espacios domésticos y a 
espacios vinculados con buenos recursos de caza y recolección, por lo que una función posible de las representaciones se relacionaría con la denotación de espacios de retorno previsto.

Al considerar exclusivamente la Puna argentina, el arte rupestre de los cazadores-recolectores se caracterizó, desde principios del Holoceno, por motivos geométrico abstracto simples (Aschero y Podestá 1986). Sin embargo, hacia los 5.500 años a.p. se agregan en Antofagasta de la Sierra figuras de circunferencias o circunferencias concéntricas con apéndices inferiores (Figura 3), junto con representaciones de figuras humanas, camélidos, felinos y aves, aunque en mínima proporción, definiendo la "modalidad estilística Quebrada Seca" (Aschero 1999). La asociación camélidos-felinos-aves es un tema particular presente a fines del Holoceno Medio en la Puna Meridional Argentina (Aschero 1998). Todos los sitios con arte rupestre coinciden con vegas o fuentes de agua permanente y con territorios aptos para la caza y/o recolección (QS1, QS2, RG3, Cc1A, PP4, LC3 y Cu5), siendo factible que el arte esté funcionando como una marca territorial.
Otro elemento interesante es que las inhumaciones (QS3 -nivel 2b2- y PP11A) y las depositaciones intencionales de conjuntos de objetos, como Cc1A y PCh1.5, coinciden con el arte rupestre en las zonas con concentración de nutrientes, por lo que es probable que esta asociación de los muertos y las ofrendas con sectores particulares del paisaje haya servido también para denotar el derecho territorial. En este sentido se han tomado las inhumaciones de cabezas removidas de sus cuerpos de la Puna Norte y Andes Centrales, relacionándolas con un culto a los ancestros o como recordatorio de relaciones intergeneracionales, que reafirman y legitiman los derechos familiares sobre el paisaje (Yacobaccio 2000). Aschero (2009) plantea que localmente se trataría de territorios no muy extensos, sujetos al control por parte de un grupo familiar o linaje, que coincidirían aproximadamente con quebradas con agua permanente.

$\mathrm{Al}$ respecto, la ocurrencia de variaciones microrregionales en las representaciones de camélidos de la "modalidad estilística Río Punilla" ha sido vinculada con una situación de territorialidad por

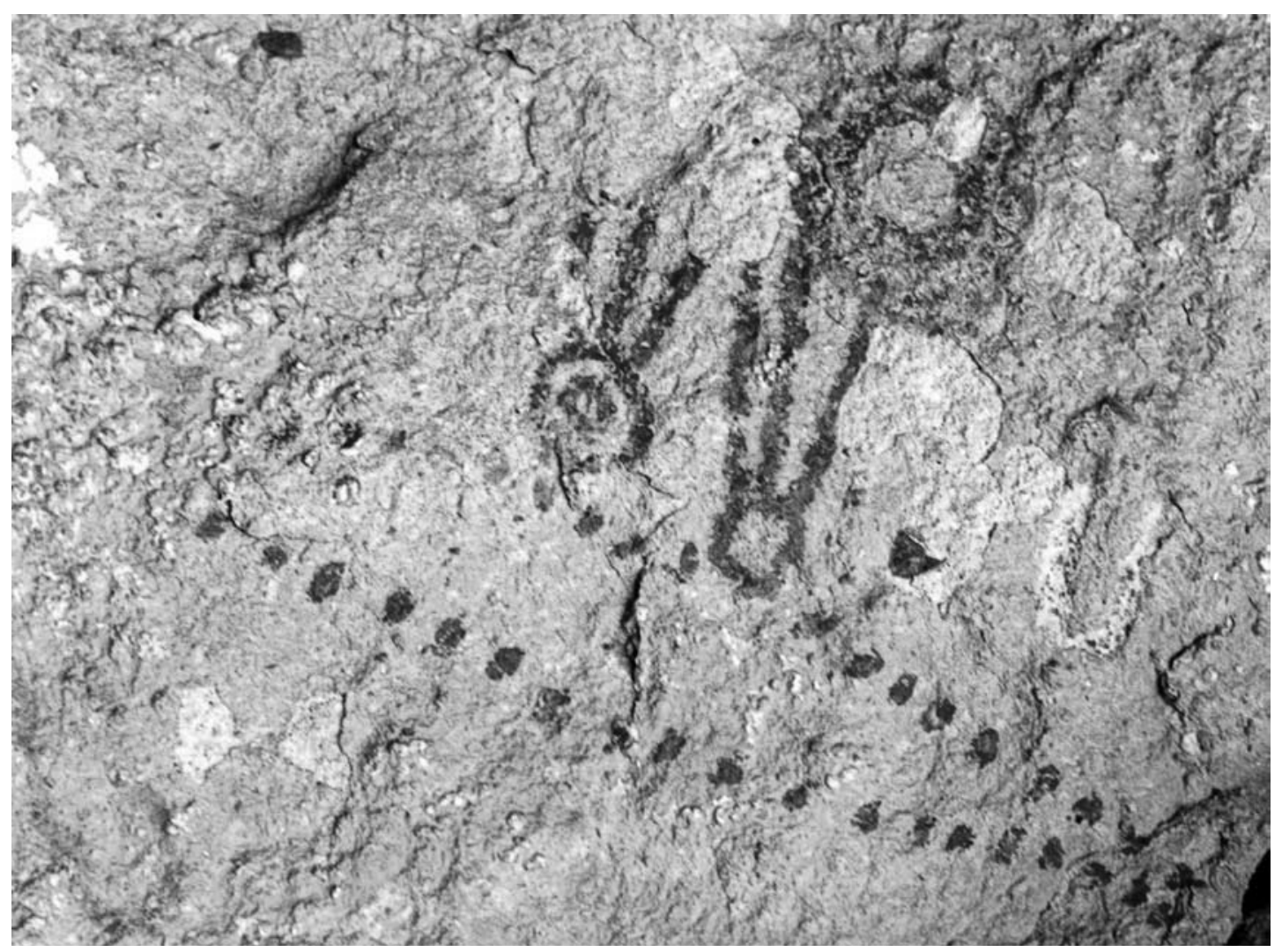

Figura 3. Circunferencias con apéndices y puntiformes. Quebrada Seca 1.

Circumferences with appendix and punctiforms. Quebrada Seca 1. 
Aschero (2007, 2009) (Figura 4), quien señala una variabilidad quebrada a quebrada en el arte rupestre local formada por diferentes "estilos" de dicha modalidad, ca. 3.500 años a.p., a modo de elementos idiosincrásicos que denotan ciertos sectores del espacio microrregional. Estos coexisten temporalmente y comparten pautas de diseño y temas, lo que surge cuando se comparan las series asignadas de sitios ubicados en distintas quebradas, como Cacao 1A, Real Grande 3, Peñas Coloradas 1 y del sitio La Torre 1 en el fondo de cuenca (Aschero 2006). De esta forma, las representaciones rupestres podrían ser marcadores de ciertos espacios y recursos por parte de segmentos sociales específicos.

Esta situación de virtual control de ciertas porciones de la microrregión por parte de grupos específicos tendría un reflejo en la utilización de materias primas empleadas en la confección de artefactos líticos tallados. Es así que entre los 4.000 y los 3.500 años a.p., en coincidencia con la cronología postulada por Aschero, se evidencia una drástica restricción en la frecuencia de artefactos manufacturados sobre Vulcanita 4 (1,99\%), una roca que se presenta en dos sectores distintos del fondo de cuenca-Los Negros (Escola 2000) y Campo Cortaderas (Elías y Tchilinguirian 2005)-.
Si se tiene en cuenta que los sitios PP4, PCh1.3 y PCh1.1 se encuentran a aproximadamente $16 \mathrm{~km}$ de las canteras identificadas, y por ende, a una distancia acorde con el rango de acción de las actividades diarias de subsistencia, no habría motivo aparente para que no se produzca tal acceso. Por esto, se considera que son pertinentes, en este caso, las diferencias observadas por Aschero en el arte rupestre del sitio La Torre, en el fondo de cuenca y el de Peñas Coloradas 1, en la "Quebrada del Río Las Pitas", donde se encuentran también las tres bases residenciales aludidas. Es muy posible, entonces, que la restricción en la utilización de dicha roca se deba a la presencia de control territorial, con grupos familiares que se apropian del acceso, por ejemplo, de recursos hídricos, vegetales y fauna de sectores específicos del área de estudio.

La territorialidad también puede expresarse en forma de diseños de artefactos distintivos (Price y Brown 1985). Así, en una escala espacial macrorregional es notoria la ausencia del empleo de la técnica de manufactura de hojas en Antofagasta de la Sierra y, en relación a ello, de las denominadas "Puntas Saladillo", que sí son ubicuas en sitios de la Puna Norte Argentina con la cronología aquí abordada (Fernández Distel 1978; Fernández 1996). También,

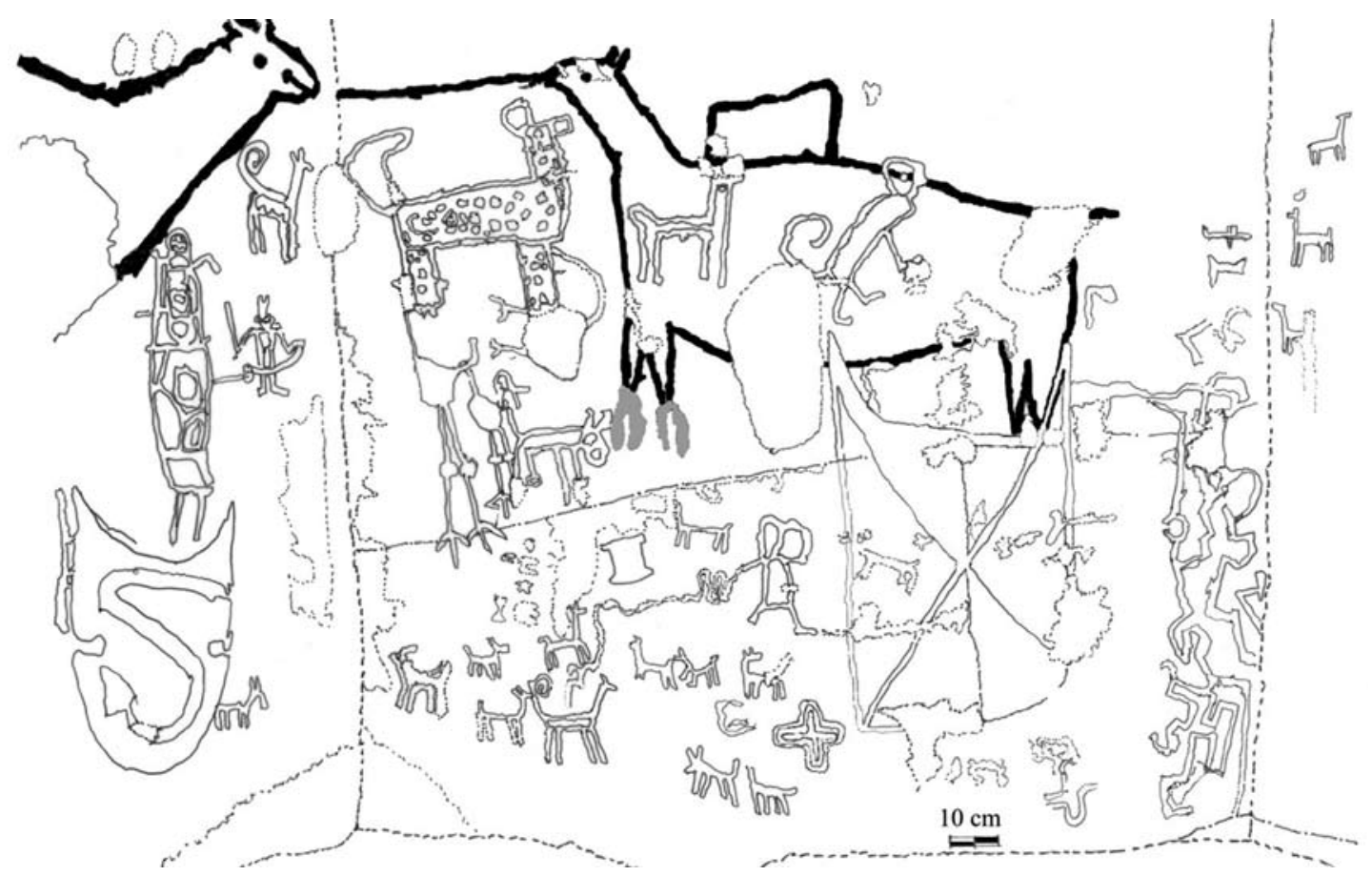

Figura 4. Camélidos Río Punilla, grabados (tomado de Aschero 2006:126; Figura 12).

Río Punilla camelids, engravings (adapted from Aschero 2006:126; Figure 12). 


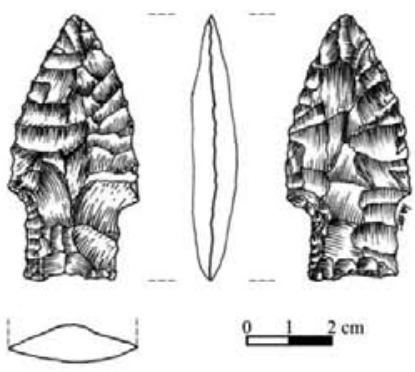

QS B.2

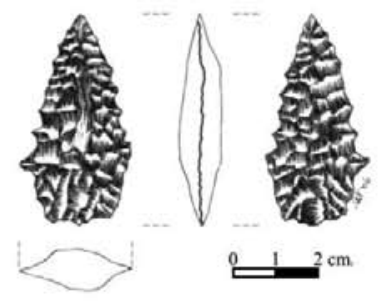

$\mathrm{PCh} \mathrm{C}$

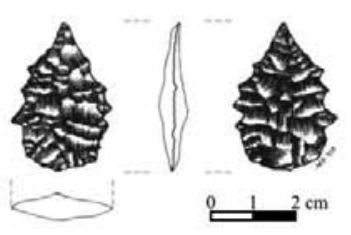

PP B

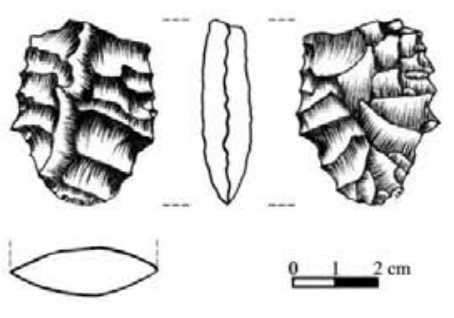

$\mathrm{PCh} \mathrm{A}$

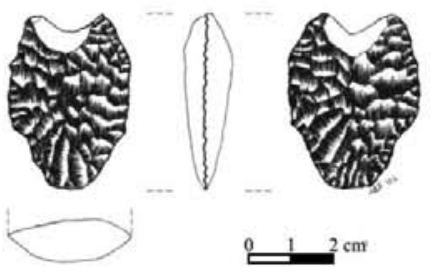

PCh D

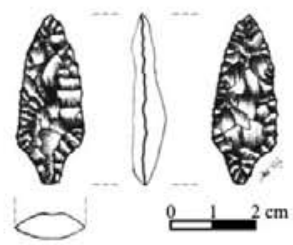

PP C

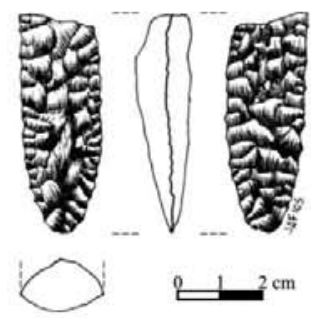

$\mathrm{PCz} \mathrm{A}$

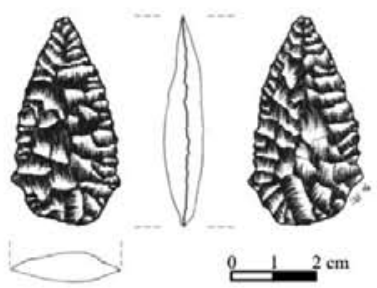

PCh B

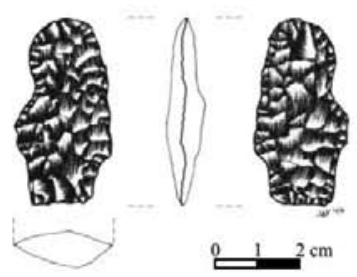

PP A

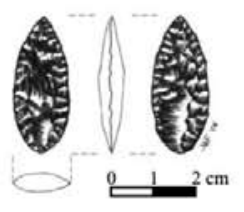

PCh E

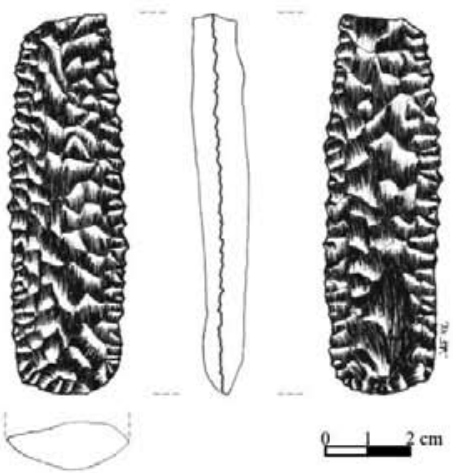

PCh F

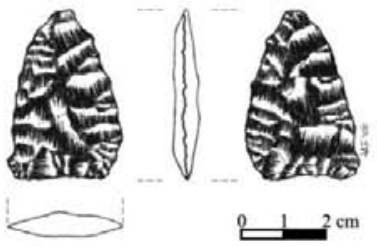

PCh G

Figura 5. Puntas de proyectil -4.000-3.500 a.p.- (tomado de Hocsman 2009, Figura 2). Projectile points -4,000-3,500 BP-(adapted from Hocsman 2009, Figure 2).

la virtual ausencia de diseños de puntas de proyectil con morfología "en mandorla" (bipunta) hacia el 3.500 a.p. $-\mathrm{N}: 1$ sobre 128 especímenes- (Hocsman 2006), cuando son relativamente frecuentes en la
Puna Norte Argentina (Aschero, Hocsman y Ratto 2010). A su vez, ciertos atributos específicos de las puntas de proyectil pueden ser considerados como particulares de Antofagasta de la Sierra (Figura 5), 
como es el caso de la regularización alterna en los pedúnculos, que consiste en series de retoques que afectan caras y bordes distintos. Esta formatización constituye un rasgo estilístico hasta el momento exclusivo del área de estudio. De ocho tipos de puntas de proyectil pedunculadas entre los $4.000 \mathrm{y}$ 3.500 años a.p. (Figura 5), cuatro poseen retoque/ microrretoque alterno, a saber: QS B.2, PP A, PCh D y PCh A (Hocsman 2006). Es más, los tipos PP A y PP B y posiblemente el QS B.2 no tendrían correlato en otras áreas de la porción meridional de los Andes Centro-Sur.

Otro aspecto de interés refiere a la diversidad de puntas de proyectil existente entre los $4.000 \mathrm{y}$ los 3.500 años a.p. Esta coexistencia de múltiples diseños excede toda posibilidad de variante cinegética en cuanto a implementación de diferentes sistemas de armas y de técnicas de caza (p.ej., Aschero y Martínez 2001), por lo que estaría dando cuenta, en realidad, de una importante cuota de variación estilística a nivel microrregional (Hocsman 2006) (Figura 5), la que, en coordenadas espaciales, podría reflejar la presencia de territorios. Como la muestra de sitios analizados hasta el momento corresponde a una sola quebrada, no es posible establecer si hay alguna vinculación entre diseños específicos y sectores particulares de la microrregión. Lo que sí sería discernible es un proceso de diferenciación social intraquebrada, vinculado con procesos identitarios al nivel de individuos o grupos (familias o linajes), por la presencia diferencial de tipos de puntas de proyectil en sitios con cronologías similares (Hocsman 2006).

\section{Subsistencia}

Antofagasta de la Sierra se caracteriza en el lapso abordado por una explotación intensiva de camélidos, al considerar el predominio absoluto de las proporciones de restos óseos de camélidos sobre otros taxones, con altísimos valores de Número de Especímenes Identificados por Taxón (NISP), en QS3 y PCh 1.1 (Elkin 1996). La explotación de este recurso básico para la subsistencia en la Puna devino en una caza especializada y en un proceso domesticatorio (Núñez 1992; Olivera 1998; Yacobaccio 2001; Yacobaccio et al. 1997-1998). Cabe destacar que la caza fue una actividad sumamente importante, aun en contextos agropastoriles plenos posteriores al 2.000 a.p. (Olivera 1998).
Hay un marcado consenso en que la domesticación de camélidos fue un proceso regional en los Andes Centro-Sur (Cartajena et al. 2007; Olivera 1998; Yacobaccio 2001; Yacobaccio et al. 1994). En el caso del área estudiada, no había evidencias osteométricas seguras de su ocurrencia; sin embargo, la ambigüedad de los resultados llevó a no descartar la posibilidad de un proceso domesticatorio local (Elkin 1996; Olivera 1998). Recientemente, el análisis osteométrico de una muestra faunística del sitio PCh1.5, fechado hacia 3.800 a.p., resultó en la identificación de un camélido similar en tamaño a un morfotipo llama (Aschero, Izeta y Hocsman 2010). Por su parte, Reigadas (2000-2002, 2008) señala, desde las evidencias de fibra, la instancia de experimentación a nivel local, involucrando un contexto de control intencional con cronología entre 4.700 y 4.500 a.p. Asimismo, el arte rupestre local está suministrando información relevante. En distintos sitios se observan, dentro de la modalidad estilística Río Punilla, camélidos de tendencia figurativo-analítica versus camélidos de tendencia figurativa-sintética y geométrica, que se diferencian, además, los primeros de los segundos, por una cierta dinámica del movimiento contra un marcado estatismo, distinguiendo camélidos silvestres y domésticos, respectivamente (Aschero 2006). Esto se vería corroborado por el hecho de contar con un camélido figurativo sintético del tipo señalado con clara evidencia de carga y bozal en el sitio Peñas Coloradas 1 (Figura 4).

Diversos autores han sugerido que la ocurrencia de la domesticación animal y la "opción pastoril" son procesos y estrategias "naturales" en la Puna, dadas las características ambientales de la misma, dándole a la agricultura un papel secundario (Muscio 2004; Olivera 1992; Yacobaccio et al. 1997-1998). No se pretende discutir aquí la importancia relativa de una estrategia sobre otra a nivel local, sino, simplemente, tratar las evidencias generadas por la Dra. Babot en relación con la presencia de cultígenos. Así, Babot (2004, 2005, 2011 en este número) realizó estudios sistemáticos sobre microfósiles en artefactos de molienda que resultaron en el hallazgo de una importante variedad de recursos vegetales comestibles, tanto silvestres como domesticados, en sitios datados entre 4.700 y 3.400 años a.p. Entre los últimos destacan Chenopodium sp. aff. C. quinoa, Oxalis tuberosa "oca", Solanum tuberosum "papa blanca" y Zea mays "maíz". Se debe remarcar que los artefactos analizados fueron recuperados 
de cuatro sitios arqueológicos, tres de los cuales son relativamente sincrónicos (PP4, PCh1.3 y PCh1.1), mientras que el restante está muy cercano temporalmente (QS3). Todas las piezas provienen de estratigrafía.

De acuerdo con Babot (2004), la práctica de la molienda en el lapso citado no sería ocasional, sino más bien regular, y planificada o programada, aunque a una escala reducida. Asimismo, para esta autora, los recursos de molienda se habrían consumido con cierta regularidad y en relativa cantidad, lo que sugeriría que tuvieron un papel importante en la subsistencia (Babot 2006).

La información procedente de los fitolitos y almidones señala, en relación a estos cultígenos, que, indudablemente, fueron procesados y seguro consumidos; sin embargo, esto no implica que fueran producidos localmente (Gil 1997-98). Un punto clave, para corroborar esto, es contar con datos que impliquen que dichos recursos no fueron "introducidos" a la microrregión vía interacción. En efecto, tales recursos pudieron provenir también de otras áreas de la Puna, o bien de la Prepuna, obtenidos por intercambio mediante acceso directo o indirecto. Las evidencias en este sentido proceden del registro macrobotánico. Así, en PCh1.3, se recuperaron tallos de una quenopodiácea doméstica (Aguirre 2007, 2009). Se destaca que Babot (2005) identificó granos de almidón y fitolitos de calcio de Chenopodium sp. en los sitios relativamente sincrónicos PCh1.1 y PP4. Este hallazgo de tallos de quinoa doméstica tiene importantes consecuencias, ya que implicaría que localmente se realizaban cosechas de este pseudocereal, lo cual podría hacerse extensivo a otros cultígenos microtérmicos (para una discusión sobre este tema ver Hocsman 2007). Podría postularse la ocurrencia de una producción a pequeña escala en la microrregión hacia el 3.600 a.p., dada la confluencia de indicadores micro y macro. Sin embargo, no es posible dilucidar si tales tareas productivas refieren a procesos de experimentación y domesticación o bien a un ingreso como práctica consolidada.

Debe destacarse que los recursos reseñados se utilizaron para la subsistencia, por ser la totalidad de los contextos de uso de tipo residencial. De esta forma, no se estaría ante una situación de uso en contextos rituales de cultígenos tempranos como se plantea, por ejemplo, para la Quebrada de Tulán, en el desierto del norte de Chile (McRostie Bustamante 2007; Núñez et al. 2006).
Puede proponerse que la presencia de ciertos cultígenos, como el maíz, se debe, en cambio, a interacción, debido a su carácter mesotérmico. Sin embargo, la existencia a nivel regional de ciertas variedades de maíz resistentes a la altura (p.ej. Abiusso y Cámara Hernández 1974), así como el mejoramiento de las condiciones ambientales generales en la microrregión hacia los 4.000-3.500 a.p. (Olivera et al. 2006) pueden haber propiciado su cultivo a nivel local.

Otro aspecto relevante es que la práctica del almacenamiento habría estado instalada, denotando una economía de retorno diferido. Esto puede afirmarse dado que los tubérculos, la quinoa y el maíz requieren ser deshidratados y almacenados para su posterior machacado y molido (Babot 1999, 2004). De esta forma, tales recursos funcionarían como un "reaseguro", destinados a prevenir o minimizar los riesgos de subsistencia de corto plazo, ya que la implementación de la molienda ocurriría durante buena parte del año (Babot 2004).

\section{Redes de interacción a largas distancias}

Es pertinente notar que el grado creciente de fijación de los grupos humanos al paisaje a escala micro señalado previamente no debió llevar necesariamente a una disminución de la circulación regional. La información disponible parecería sustentar, justamente, una micromovilidad reducida y una macromovilidad funcionando a pleno a fines del Holoceno Medio y durante el Holoceno Tardío (Hocsman 2006). Dadas las distancias involucradas en la interacción, esta habría constituido una red de circulación regional de recursos, información y conocimientos. De hecho, el "área de captación" de los insumos es realmente amplia, incluyendo distintos sectores de la Puna Meridional Argentina, los Valles y Quebradas Mesotermales, las Yungas, la Llanura Chaqueña y la costa del Océano Pacífico e implicando distancias que superan los $500 \mathrm{~km}$.

Las evidencias de interacción a largas distancias son abundantes y variadas en el lapso abordado, incluyendo, entre otros, información sobre arte rupestre y tecnofacturas diversas y el ingreso de recursos de clara naturaleza no local. A modo de ejemplo se presentan casos específicos. Así, se señalan las estrechas similitudes de diseños de camélidos del sitio Cf1 con aquellos de la serie estilística Taira-Tulán del ámbito atacameño (Aschero 1999). Por su parte, ciertos diseños de 
puntas de proyectil se presentan recurrentemente en distintos ámbitos de la Puna argentina y de la Puna y circumpuna chilena, como los tipos PCh E, PCz A y PP C (Hocsman 2006, 2009). Como último ejemplo, se mencionan los elementos alóctonos recuperados como parte del ajuar de un enterratorio en el sitio PP11A. El neonato, entre otros elementos, presentaba un cuchillo de valva de Anodontites trapezialis, un molusco de agua dulce que correspondería a la llanura chaqueña, situada a más de $200 \mathrm{~km}$ de distancia. Este había sido dispuesto como pendiente, sostenido desde su cuello por un cordel embarrilado en tiento con un alma de fibra vegetal de Acrocomia chunta, proveniente de las Yungas jujeñas, a unos $600 \mathrm{~km}$ al noreste (Aschero 2010; Aschero et al. 1999).

Los elementos alóctonos fueron utilizados para una diversidad de actividades, como materia prima para la confección de artefactos asociados a actividades de subsistencia -como obsidiana para la elaboración de instrumentos o astiles y/o intermediarios sobre Chusquea lorentziana-, para la alimentación -taxones silvestres y domesticados diversos-, y formaron parte de una tecnología de prestigio, posiblemente relacionada con el ritual -como sería el caso de artefactos sobre valva, mate y cordeles de palmera-. Dentro de los elementos comestibles se recuperaron tanto vegetales silvestres como cultígenos. Entre los primeros destacan Opuntia sp. "penca", Juglans australis "nuez" y Prosopis sp. "algarrobo", mientras que entre los segundos se pueden citar Canna edulis "achira", Cucurbita sp., Lagenaria siceraria "mate" y Amaranthus caudatus / mantegazzianus "amaranto" (Babot 2004, 2005). Esto plantea un escenario de obtención de recursos domesticados por interacción con grupos productores de los valles y quebradas y de las Yungas del Noroeste Argentino, con fechas tan tempranas como ca. 3.600 a.p.

\section{El proceso transicional local desde los artefac- tos líticos tallados y la alfarería}

Uno de los cambios tecnológicos más importantes en los artefactos líticos tallados está relacionado con la tendencia a invertir menor esfuerzo en su manufactura, ya que se registra una disminución con el paso del tiempo de la utilización de técnicas que implican una formatización de las caras y un consecuente un aumento de frecuencia de las técnicas que afectan sólo los bordes de las piezas
(Hocsman 2010). Una de las consecuencias más importantes de esto fue la desaparición del adelgazamiento bifacial y de los bifaces asociados, de los conjuntos de artefactos. La opción por estrategias tecnológicas con bajos costos de producción en cuanto a requerimientos de tiempo, energía y destreza técnica permite rotular el proceso transicional en relación con los artefactos líticos como de "simplificación tecnológica". Asimismo, esto tuvo como correlato importantes cambios en el conocimiento tecnológico a lo largo del tiempo, en lo que respecta al "saber", a los requerimientos de destreza técnica y a la aplicación de sistemas de enseñanza (Hocsman 2006).

Otras evidencias están en consonancia con la perspectiva de una simplificación de los artefactos líticos tallados. Las mismas refieren a la complejidad del instrumental y a la presencia de artefactos compuestos, ya que, con respecto a la primera, no sólo disminuye el número de filos y/o puntas por pieza, sino que las piezas conformadas por una sola parte (simples) ven incrementada su importancia a través del tiempo y, en cuanto a los segundos, la frecuencia de piezas con filos y/o puntas distintas se ve marcadamente reducida (Hocsman 2010).

Otra serie de procesos importantes en la transición de la caza-recolección a la producción agropastoril a nivel local son las variaciones en la diversidad y en el diseño de los instrumentos. Al respecto, tomando nuevamente en consideración la información de las clases técnicas, se evidencia que no sólo se produjeron cambios substanciales en la forma de producir los artefactos formatizados, sino que también disminuyó considerablemente el número de alternativas tecnológicas utilizadas, ya que de ocho clases empleadas se pasó a solo tres hacia el 2.000 a.p., involucrando una restricción importante en la "diversidad tecnológica" a través del tiempo.

A su vez, del tratamiento de los grupos y subgrupos tipológicos resulta la recurrencia de los primeros en el tiempo. Así, la "diversidad tipológica" se mantiene en el lapso abordado al tratar instrumentos vinculados con procesamiento/consumo, mientras que aquella vinculada a labores extractivas -puntas de proyectil- se vio drásticamente disminuida; al mismo tiempo, las labores productivas llevaron a un incremento de la diversidad, con la irrupción de las palas/azadas (Escola 2000) o los cuchillos/ raedera de módulo grandísimo (Escola y Hocsman 2009) post 2.000 a.p. 
Con respecto a las puntas de proyectil, se observa una marcada estandarización en diversos aspectos tecnológicos y tipológicos en las piezas de contextos agropastoriles plenos con respecto a las características de las puntas de proyectil de los cazadores-recolectores transicionales (Hocsman 2009). Sin embargo, esto no significa que no haya vinculaciones. Así, dos aspectos dan cuenta de continuidad. Por un lado, la tendencia a la utilización cada vez mayor de la obsidiana con el paso del tiempo y, por el otro lado, las vinculaciones genéticas en función de un proceso de invención entre las puntas de proyectil definidas como TM PPC y CChMA (Hocsman 2009), correspondiendo estas últimas a los diseños pedunculados típicos agropastoriles (Escola 2000).

En lo que respecta a la alfarería, las evidencias disponibles hasta el momento en el área de estudio estarían señalando el desarrollo vía experimentación y/o introducción de esta tecnología. Destaca, en este sentido, un antecedente de la cerámica propiamente dicha recuperado en el sitio PCh1.5, datado ca. 3.800 años a.p. Específicamente, es un fragmento de la pared de un recipiente de forma no determinable, compuesto por una estructura de haces de Cortaderia speciosa, recubiertos en ambas caras por una mezcla de material biogénico $\mathrm{y}$ arcilla, probablemente un suelo con componentes arcillosos. Los estudios fisicoquímicos realizados con la pasta y la fibra permiten establecer que la pieza pudo estar, eventualmente, bajo efecto térmico suave, con temperaturas inferiores a $200^{\circ} \mathrm{C}$, o que directamente no estuvo sometida a tratamiento térmico (Cremonte et al. 2009). Dicha cubierta habría servido para impermeabilizar y resguardar el contenido del recipiente. Este fragmento guarda similitudes con un recipiente recuperado en el sitio Inca Cueva 7, en la Puna jujeña, con cronología de ca. 4.000 a.p. (Aguerre et al. 1973). Este último se diferencia del primero en el tipo de armadura empleada, ya que se trata de un entramado de varillas curvas y rígidas, y en la cubierta, debido a que reviste sólo la cara externa.

A esto se suma la presencia de alfarería cocida en distintos sitios adscribibles a la transición, aunque, se destaca, se requiere de la realización de análisis tecnológicos y tipológicos específicos y/o corroborar la cronología. Así, Aschero et al. (1999) y Aschero (2009) hacen referencia al hallazgo de dos fragmentos de un tubo cerámico en el borde externo de la oquedad que contenía el fardo funerario del sitio PP11A, planteando la asociación con el mismo, por lo que estarían datados entre los 3.600 y los 3.200 años a.p. Una serie de tiestos se registraron, también, en las excavaciones sistemáticas realizadas en PCh1.6, un sitio a cielo abierto unicomponente, que cuenta con materiales líticos que por sus características tecnológicas y tipológicas son similares a los de los sitios cercanos PCh1.1 y PCh1.3, datados hacia los 3.600 a.p.

Estas fechas son coincidentes con la presencia de cerámica en otros contextos arqueológicos de la Puna y circumpuna; diversos sitios con cronología entre 3.600 y 2.900 años a.p. cuentan con esta tecnofactura. En la Puna jujeña se encuentran, por ejemplo, Tomayoc, Inca Cueva alero 1 y Cueva de Cristóbal, con fechados entre 3.000 y 2.800 años a.p. aproximadamente (Fernández 1988-89; García 1995); en la Puna salteña, por su parte, es el caso del sitio Ramadas (Estructura 1), fechado hacia los 3.600 años a.p. (Muscio 2004); finalmente, en la Quebrada de Tulán (Chile), en los sitios Tulán 94, 54 y 85, fechados entre 3.400 y 2.500 a.p. (Núñez et al. 2006).

\section{Consideraciones Finales}

El abordaje de la variabilidad y el cambio en los cazadores-recolectores es de particular interés y relevancia en la porción meridional de los Andes Centro Sur, puesto que se registran modificaciones sustanciales en los modos de vida, como fue el tránsito de la caza-recolección a la conformación de sociedades productoras plenas. Esto no implica, sin embargo, considerar a la agricultura y al pastoralismo como el próximo estadio de desarrollo dirigido en la historia de los cazadores-recolectores (RowleyConwy 2001). De hecho, los trabajos arqueológicos a lo largo del Noroeste Argentino están comenzando a señalar múltiples escenarios con respuestas locales y trayectorias históricas particulares. En el caso de Antofagasta de la Sierra, las evidencias reseñadas dan cuenta de un proceso transicional local, pero, en otras áreas del Noroeste Argentino, los escenarios pudieron ser múltiples: situaciones transicionales que culminan en una producción plena o no; cazadores-recolectores con estrategias de obtención de recursos domesticados estables y de largo plazo, mediando mecanismos de interacción con grupos agropastoriles locales (coexistencia) o foráneos, sobre la base de implementación de circuitos de mediana y gran distancia; o bien cazadores-recolectores 
con dependencia exclusiva de recursos animales y vegetales silvestres persistentes y sincrónicos con los procesos transicionales.

Es indudable que el estudio de la variabilidad sólo es posible a través del análisis de casos. De esta forma, el abordaje de la secuencia arqueológica de Antofagasta de la Sierra constituye una oportunidad para evaluar los procesos de cambio en cazadoresrecolectores.

De la información obtenida hasta el momento para dicha área de estudio, con respecto a la explotación de recursos animales, podría definirse una "estrategia predominante" (sensu Yacobaccio et al. 1997-1998) de caza-recolección exclusiva para aquellos contextos anteriores a los 5.000 años a.p., aproximadamente, y de caza-recolección/domesticación con posterioridad a esa fecha. Utilizando la terminología de Smith (2001), ca. 4.500 a.p. se estaría ante una situación de "economía productiva de bajo nivel, sin domesticados". El punto es dilucidar cuándo se pasó a una "economía productiva de bajo nivel, con domesticados". Por el momento, no se cuenta con evidencias contextuales (p.ej., corrales) que remitan a la presencia a nivel microrregional de camélidos domesticados, pero sí osteométricas 3.800 a.p., aunque refieren a un solo sitio, y de experimentación sobre el análisis de fibra hacia los 4.700 años a.p. A partir de lo expresado, podría considerarse, entonces, la ocurrencia de una "economía productiva de bajo nivel, con domesticados", en relación con lo animal, tomando como base la fecha de los datos osteométricos, lo cual, se destaca, es perfectamente compatible con los datos obtenidos en otras áreas de la Puna argentina (Yacobaccio 2001; Yacobaccio et al. 1997-1998).

Dado que puede hablarse de pastoralismo cuando hay un sistema productivo en pleno funcionamiento (Reigadas 2000-2002; Yacobaccio et al. 1997-1998), es de suma importancia evaluar la ocurrencia de este último, así como su cronología. Así, estrictamente en base a la información obtenida hasta el momento, la práctica pastoril estaría presente en Antofagasta de la Sierra recién hacia los 2.100 a.p. Se propone, entonces, una estrategia predominante de cazarecolección/pastoreo entre los 3.500 y los 2.000 años a.p. Por su parte, el cambio a una estrategia de pastoreo/caza-recolección tiene bases para ser definida hacia los 2.000 años a.p.

Con respecto a los recursos vegetales domesticados, resulta sugerente que buena parte de los mismos son de tipo microtérmico (quinoa, papa, oca), por lo que están adaptados concretamente a las condiciones ambientales de los desiertos del altura. Se destaca, sin embargo, que no hay evidencias como para sustentar la ocurrencia de procesos de domesticación vegetal a nivel local. Por esto, se plantea que no es posible hipotetizar la ocurrencia de una "economía productiva de bajo nivel, sin domesticados", siguiendo la ya mencionada terminología de Smith (2001), implicando, por ende, prácticas de manejo y protección de plantas silvestres, pero sí de una "economía productiva de bajo nivel, con domesticados" ca. 3.500 años a.p. La información disponible permite aseverar la presencia de un sistema agrícola pleno hacia los 2.000 años a.p.

Recapitulando, al conjugar las evidencias, resulta que los contextos con cronología anterior al 5.000 a.p. estarían definidos por una situación de caza-recolección exclusiva. Posteriormente, entre los 4.700 y 4.500 años a.p., se estaría en presencia de caza-recolección más una "economía productiva de bajo nivel, sin domesticados" -con prácticas de manejo y protección de camélidos silvestres y sin poder aseverar experimentación con recursos vegetales-. El lapso 4.000-3.500 años a.p., a su vez, estaría definido por la combinación de cazarecolección/“economía productiva de bajo nivel, con domesticados", tanto en lo que respecta a camélidos domesticados como a cultígenos, involucrando, posiblemente, pastoralismo (i?). Finalmente, el segmento 2.100-1.500 a.p. estaría representado por estrategias pastoriles-agrícolas/caza-recolección. Los cazadores-recolectores transicionales se encuentran localmente, entonces, en el conjunto de situaciones entre la caza-recolección exclusiva y la estrategia predominante de agricultura-pastoreo. Ciertamente, con la continuidad de las investigaciones es posible que se logre información sobre prácticas domesticadoras que retrotraigan las fechas aquí presentadas, dando como resultado procesos mucho más antiguos que los hoy avizorados.

Otras características relevantes del proceso transicional remiten a evidencias del arte rupestre, de los enterratorios/ofrendas y de los artefactos líticos, entre otros, que permiten sostener presencia de marcas territoriales, producto de una regionalización asociada al surgimiento de territorios fijos, que adquiere sentido al tener en cuenta la información sobre movilidad residencial reducida.

Los datos sobre arquitectura en piedra en reparos rocosos, domesticación animal, utilización 
de cultígenos, vinculaciones genéticas en puntas de proyectil, experimentación alfarera, etc. son consistentes y aportan a la idea de continuidad entre grupos cazadores-recolectores y sociedades agropastoriles en este sector de los Andes Centro Sur. El cúmulo de información obtenida sustenta la idea de un proceso transicional local y no un reemplazo poblacional y/o la llegada de "paquetes" de rasgos culturales que reemplazan anteriores, coparticipado con otras áreas de la Puna Argentina y del desierto del norte de Chile, siendo esto visible, por ejemplo, al considerar los diseños de puntas de proyectil de amplia distribución areal y las representaciones de camélidos marcadamente afines a Taira-Tulán en Antofagasta de la Sierra.

La transición conlleva a que los cazadoresrecolectores incorporaron prácticas agrícolas y/o ganaderas en su estrategia de vida, siendo esto lo acontecido en el área de estudio. $\mathrm{Al}$ respecto, no hay diferencias en la organización del asentamiento, la movilidad o la tecnología que permitan aseverar la coexistencia a nivel microrregional de grupos cazadores-recolectores y agropastoriles.

Más allá de las convergencias con otras áreas puneñas, por ejemplo, en cuanto a cronología, a la presencia de alfarería y de diseños de artefactos líticos o a la disminución de la movilidad residencial, son significativas las particularidades de la secuencia de Antofagasta de la Sierra. Entre éstas, se pueden mencionar la importancia de los recursos vegetales domesticados en la subsistencia, en relación con otras áreas de la Puna Argentina como Susques, donde estarían ausentes (Yacobaccio et al. 1998-99) o en la Quebrada de Tulán, con un papel básicamente ritual de los cultígenos (McRostie Bustamante 2007), o la ausencia de conglomerados residenciales a cielo abierto como los de la Quebrada de Tulán (Núñez et al. 2006).
En este trabajo se remarcó la idea de continuidad de los procesos socioculturales en la Puna argentina, con las sociedades cazadoras-recolectoras como antecedentes ineludibles de la conformación de las sociedades agrarias locales (Aschero 1994, 2010; Hocsman 2006). Dicha continuidad involucró la transmisión generacional de información y prácticas del hacer a través del tiempo, una situación que, de hecho, no deja de lado el cambio (Aschero 2010). El no adherir a reemplazos poblacionales y/o a la llegada de "paquetes de rasgos" no implica, no obstante, no considerar como altamente plausible (y necesaria) la llegada de hombres y mujeres a la Puna por medio de redes de interacción en una dinámica de reproducción social y biológica de largo plazo.

Por otra parte, la continuidad no debe ser entendida como uniformidad. Las evidencias aquí suministradas muestran diferencias y semejanzas desde diversas líneas con otras áreas de la porción meridional de los Andes Centro Sur, que pueden ser entendidas en términos de "elecciones" (Lemonnier 1993). Este ámbito de las elecciones tomadas en relación a qué y cómo hacer las cosas es un punto a ser explorado y se considera que debe ser parte de la agenda arqueológica, puesto que permitirá entender en cada caso el particular entramado de lo que era "tradicional" para la sociedad y si los nuevos desarrollos resultaron de la recombinación de elementos existentes, de innovaciones u obtenidos vía interacción con otros grupos.

Agradecimientos: A los evaluadores del trabajo por sus sugerencias y comentarios. El mismo se desarrolló en el marco de los Proyectos FONCYTPICT N 38127 y PIP-CONICET No 6398, dirigidos por Carlos Aschero, y FONCYT-PICT No 2264, dirigido por María del Pilar Babot.

\section{Referencias Citadas}

Abiusso, N. y J. Cámara Hernández 1974. Los maíces autóctonos de la Quebrada de Humahuaca (Jujuy, Argentina), sus niveles nitrogenados y su composición en aminoácidos. Revista de la Facultad de Agronomía Tomo L:1-25.

Aguerre, A., A. Fernández Distel y C.A. Aschero 1973. Hallazgo de un sitio acerámico en la Quebrada de Inca Cueva (Provincia de Jujuy). Relaciones de la Sociedad Argentina de Antropología VII:197-235.

Aguirre, M.G. 2005. Arqueobotánica del Sitio Peñas Chicas 1.3, Antofagasta de la Sierra, Catamarca-Argentina. Tesis para optar al grado de Arqueóloga, Facultad de Ciencias Naturales e Instituto Miguel Lillo, Universidad Nacional de Tucumán, Tucumán.

- - - 2007. Arqueobotánica del sitio Peñas Chicas 1.3 (Antofagasta de la Sierra, Catamarca, Argentina). En Paleoetnobotánica del Cono Sur: Estudios de Casos y Propuestas Metodológicas, compilado por B. Marconetto, M.P. Babot y N. Oliszewski, pp. 179-195. Ferreira Editor, Córdoba.

- - - 2009. Conocimiento y uso de los recursos leñosos en la Puna meridional argentina. Actas de las III Jornadas de 
Jóvenes Investigadores UNT. Versión CD-ROM. San Miguel de Tucumán.

Aldenderfer, M. 1998. Montane Foragers. Asana and the SouthCentral Andean Archaic. University of Iowa Press, Iowa.

Aschero, C.A. 1994. Reflexiones desde el Arcaico Tardío (60003000 AP). Rumitacana. Revista de Antropología 1:13-17.

- - - 1998. Arte y arqueología: una visión desde la Puna argentina. Chungara 28:175-197.

- - - - 1999. El arte rupestre del desierto puneño y el noroeste argentino. En Arte Rupestre en los Andes de Capricornio, editado por J. Berenguer y F. Gallardo, pp. 97-135 Museo Chileno de Arte Precolombino, Santiago.

- - - 2006. De cazadores y pastores. El arte rupestre de la modalidad Río Punilla en Antofagasta de la Sierra y la cuestión de la complejidad en la Puna meridional argentina. En Tramas en la Piedra. Producción y Usos del Arte Rupestre, editado por D. Fiore y M. Podestá, pp. 103-140. World Archaeological Congress, Sociedad Argentina de Antropología, Asociación de Amigos del Instituto Nacional de Antropología, Buenos Aires.

- - - 2007. Iconos, huancas y complejidad en la Puna Sur Argentina. En Producción y Circulación Prehispánicas de Bienes en el Sur Andino, compilado por, A. Nielsen, M.C. Rivolta, V. Seldes, M. Vázquez y P. Mercolli, pp. 135-165. Editorial Brujas, Córdoba.

- - - 2010. Arqueologías de Puna y Patagonia centro-meridional: Comentarios generales y aporte al estudio de los cazadoresrecolectores en los proyectos dirigidos desde el IAM (1991-2009). En Rastros en el Camino. Trayectos e Identidades de una Institución, editado por C. Aschero, P. Arenas y C. Taboada, Edunt, San Miguel de Tucumán, en prensa.

Aschero, C.A., A. Izeta y S. Hocsman 2010. New data on local South-American camelid domestication. Osteometry at Peñas Chicas 1.5 (Antofagasta de la Sierra, Catamarca, Argentina). International Journal of Osteoarchaeology, en referato.

Aschero, C.A., D. Elkin y E. Pintar 1991. Aprovechamiento de recursos faunísticos y producción lítica en el precerámico tardío. Un caso de estudio: Quebrada Seca 3 (Puna Meridional Argentina). Actas XII Congreso Nacional de Arqueología Chilena 2, pp. 101114 Sociedad Chilena de Arqueología, Santiago.

Aschero, C.A., P.S. Escola, S. Hocsman y J.G. Martínez 20022004. Recursos líticos en escala microrregional. Antofagasta de la Sierra, 1983-2001. Arqueología 12:9-36.

Aschero, C.A., L. Manzi y G. Gómez 1993-94. Producción lítica y uso del espacio en el nivel 2b4 de Quebrada Seca 3. Relaciones de la Sociedad Argentina de Antropología XIX:191-214.

Aschero, C.A. y J. Martínez 2001. Técnicas de caza en Antofagasta de la Sierra, Puna Meridional Argentina. Relaciones de la Sociedad Argentina de Antropología XXVI:215-241.

Aschero, C.A. y M.M. Podestá 1986. El arte rupestre en asentamientos precerámicos de la Puna argentina. Runa XVI:29-57.

Aschero, C.A., S. Hocsman y N. Ratto 2010. Las puntas de proyectil de Inca Cueva 7 (Puna de Jujuy, Argentina): Caracterización tecno-tipológica y distribución macro-regional. Manuscrito en posesión del autor.
Aschero, C.A., R. Zurita, M.G. Colaneri y A. Toselli 1999. El Bebe de la Peña. Actas del XIII Congreso Nacional de Arqueología Argentina, pp. 329-338. Cabildo Histórico de la Ciudad de Córdoba

Babot, M.P. 1999. Un Estudio de Artefactos de Molienda. Casos del Formativo. Tesis para optar al título de arqueóloga, Facultad de Ciencias Naturales e Instituto Miguel Lillo, Universidad Nacional de Tucumán, Tucumán.

- - - 2004. Tecnología y Utilización de Artefactos de Molienda en el Noroeste Prehispánico. Tesis para optar al grado de Doctor en Arqueología, Facultad de Ciencias Naturales e Instituto Miguel Lillo, Universidad Nacional de Tucumán, San Miguel de Tucumán.

- - - 2005. Plant resource processing by Argentinean Puna hunter-gatherers (ca. 7000-3200 A.P.). The Phytolitharien. Bulletin of the Society for Phytolith Research 17:9-10.

- - - 2006. El papel de la molienda en la transición hacia la producción agropastoril: un análisis desde la Puna Meridional argentina. Estudios Atacameños 32:75-92.

- - - 2009. Movilidad y artefactos de molienda en Antofagasta de la Sierra, Puna Meridional Argentina (ca. 6500-1100 AP). En Artefactos Líticos, Movilidad y Funcionalidad de Sitios: Problemas y Perspectivas, editado por P. Escola y S. Hocsman. John and Erika Hedges Ltd., BAR Internacional Series, Oxford, en prensa.

- - - 2011. Cazadores-recolectores de los Andes Centro-Sur y procesamiento vegetal. Una discusión desde la Puna Meridional argentina (ca. 7.000-3.200 años a.p.). Chungara Revista de Antropología Chilena 43:413-432.

Babot, M.P., C.A. Aschero, S. Hocsman, M.C. Haros, L.G.G. Baroni y S.V. Urquiza 2006. Ocupaciones agropastoriles en los Sectores Intermedios de Antofagasta de la Sierra (Catamarca): Un análisis desde Punta de la Peña 9.I. Comechingonia 9:57-75.

Barnard, A. (ed.) 2004. Hunter-Gatherers in History, Archaeology and Anthropology. Berg Publishers, Oxford.

Bodley, J. 1999. Hunter-gatherers and the colonial encounter. En The Cambridge Encyclopedia of Hunters and Gatherers, editado por R. Lee y R. Daly, pp. 465-472. Cambridge University Press, Cambridge.

Cartajena, I., L. Núñez y M. Grosjean 2007. Camelid domestication on the western slope of the Puna of Atacama, northern Chile. Anthropozoologica 42:155-173.

Cremonte, M.B., I.L. Botto, M.E. Canafoglia, S. Hocsman, M.F. Rodríguez, C.A. Aschero y D. Gazzoli 2009. Una nueva tecnología en cazadores-recolectores transicionales de la Puna Argentina. Caracterización de un recipiente con fibra vegetal. Actas del Tercer Congreso Argentino de Arqueometría y Segundas Jornadas Nacionales para el Estudio de Bienes Culturales, en prensa.

Elías, A.M. y P. Tchilinguirian 2005. Aplicación del análisis petrográfico en recursos líticos (Antofagasta de la Sierra, Provincia de Catamarca, Puna Meridional Argentina). Metodologías Científicas Aplicadas al Estudio de los Bienes Culturales. Primer Congreso Argentino de Arqueometría, pp. 208-217. Escuela de Antropología, Facultad de Humanidades y Artes, Universidad Nacional de Rosario, Rosario. 
Elkin, D. 1996. El uso del recurso fauna por los primeros habitantes de Antofagasta de la Sierra (Puna de Catamarca). Actas del I Congreso de Investigación Social. Región y Sociedad en Latinoamérica. Su problemática en el NOA, pp. 202-209. Facultad de Filosofía y Letras, Universidad Nacional de Tucumán. San Miguel de Tucumán.

Escola, P.S. 2000. Tecnología Lítica y Sociedades Agro-pastoriles Tempranas. Tesis para optar al grado de Doctor en Filosofía y Letras, Facultad de Filosofía y Letras, Universidad de Buenos Aires, Buenos Aires.

Escola, P.S. y S. Hocsman 2009. Circulación macroregional de un diseño artefactual en contextos agropastoriles: El caso de los cuchillos/raederas de módulo grandísimo. En Arqueología de las Tierras Altas de Argentina. Evolución y Cambio Cultural, editado por H. Muscio y G. López, pp. British Archaeological Reports, en prensa.

Fernández Distel, A.A. 1978. Nuevos hallazgos precerámicos en la Región de las Salinas Grandes, Puna de Jujuy, Argentina. Revista del Instituto de Antropología 6:15-62.

Fernández, J. 1988-89. Ocupaciones alfareras (2.860ะ160 años a.p.) en la Cueva de San Cristóbal, Puna de Jujuy, Argentina. Relaciones de la Sociedad Argentina de Antropología XVII (2), Nueva Serie:139-178.

- - - 1996. Potrero de Caballo Muerto: Aspectos arqueológicos, cronológicos y paleoambientales del Precerámico Tardío en el ecosistema hidrófilo de las vegas puneñas. Revista del Museo de Historia Natural de San Rafael XXV:23-51.

García, L.C. 1995. Las primeras cerámicas en la Puna de Jujuy. Cuadernos de la Facultad de Humanidades y Ciencias Sociales 5:75-80.

Gil, A.F. 1997-98. Cultígenos prehispánicos en el sur de Mendoza. Discusión en torno al límite meridional de la agricultura andina. Revista Relaciones de la Sociedad Argentina de Antropología XXII-XXIII:295-318.

González, O. 1992. Geología de la Puna Austral entre los $25^{\circ} 15^{\prime}$ a $26^{\circ} 30^{\prime}$ 'de Latitud Sur y los 66 $25^{\circ}$ ' a 68 $00^{\circ}$ ' de Longitud Oeste, provincias de Catamarca y Salta, Argentina. Acta Geológica Lilloana 17:63-88.

Harris, D.R. y G.C. Hillman (eds.). 1989. Foraging and Farming. The Evolution of Plant Exploitation. One World Archaeology 13. Unwin Hyman, London.

Hocsman, S. 2002. ¿Cazadores-recolectores complejos en la puna meridional argentina? Entrelazando evidencias del registro arqueológico de la microrregión de Antofagasta de la Sierra (Catamarca). Relaciones de la Sociedad Argentina de Antropología XXVII:193-214.

- - - 2006. Producción Lítica, Variabilidad y Cambio en Antofagasta de la Sierra -ca. 5500-1500 AP-. Tesis para optar al grado de Doctor en Ciencias Naturales, Facultad de Ciencias Naturales y Museo, Universidad Nacional de La Plata, La Plata.

- - - 2007. Aportes del sitio Peñas Chicas 1.3 a la arqueología de fines del Holoceno Medio de Antofagasta de la Sierra (Catamarca, Argentina). Cazadores-Recolectores del Cono Sur 2:167-189.
- - - 2009. Cambios en las puntas de proyectil durante la transición de cazadores-recolectores a sociedades agro-pastoriles en Antofagasta de la Sierra (Puna argentina). Arqueología 16, en prensa.

- - - 2010. La transición de la caza-recolección a la producción agropastoril en Antofagasta de la Sierra (Puna Meridional Argentina) vista desde la tecnología lítica. Chungara Revista de Antropología Chilena, en referato.

Kelly, R.L. 1992. Mobility/sedentism: concepts, archaeological measures and effects. Annual Review of Anthropology 21:43-66.

- - - 1995. The Foraging Spectrum: Diversity in Hunter-Gatherer Lifeways. Smithsonian Institution Press, Washington D.C.

Lee, R. y R. Daly 1999. Foragers and others. En The Cambridge Encyclopedia of Hunters and Gatherers, editado por R. Lee y R. Daly, pp. 1-19. Cambridge University Press, Cambridge.

Lemonnier, P. 1993. Introduction. En Technological Choices. Transformation in Material Cultures since the Neolithic, editado por P. Lemonnier, pp. 1-35. Routledge, London y New York.

Manzi, L.M. 2006. Estrategias y Formas de Uso del Espacio en Poblaciones Cazadoras Recolectoras de la Puna Meridional Argentina. BAR International Series 1465, Archaeopress, Oxford.

Martínez, J.G. 2003. Ocupaciones Humanas Tempranas y Tecnología de Caza en la Microrregión de Antofagasta de la Sierra (10000-7000 AP). Tesis para optar al grado de Doctor en Arqueología, Facultad de Ciencias Naturales e Instituto Miguel Lillo, Universidad Nacional de Tucumán, Tucumán.

McRostie Bustamante, V. 2007. La Transición Arcaico Formativo en la Quebrada Tulán. Sur del Salar de Atacama, Chile. Evidencias Arqueobotánicas. Memoria para optar al título profesional de arqueóloga, Departamento de Antropología, Facultad de Ciencias Sociales, Universidad de Chile, Santiago.

Muscio, H. 2004. Dinámica Poblacional y Evolución Durante el Período Agroalfarero Temprano en El Valle de San Antonio de los Cobres, Puna de Salta, Argentina. Tesis para optar al grado de Doctor en Filosofía y Letras, Facultad de Filosofía y Letras, Universidad de Buenos Aires, Buenos Aires.

Núñez, L. 1992. Ocupación arcaica en la Puna de Atacama: secuencia, movilidad y cambio. En Prehistoria Sudamericana. Nuevas Perspectivas, editado por B. Meggers, pp. 283-307. Taraxacum, Washington.

Núñez, L., I. Cartajena, C. Carrasco, P. de Souza y M. Grosjean 2006. Emergencia de comunidades pastoralistas formativas en el sureste de la Puna de Atacama. Estudios Atacameños. Arqueología y Antropología Surandinas 32:93-117.

Núñez, L., M. Grosjean e I. Cartajena 1999. Un ecorefugio oportunístico en la Puna de Atacama durante eventos áridos del Holoceno Medio. Estudios Atacameños 17:125-174.

- - - 2001. Human dimensions of Late Pleistocene/Holocene arid events in Southern South America. En Interhemispheric Climate Linkages, editado por V. Markgraf, pp. 105-117. Academic Press.

Olivera, D.E. 1992. Tecnología y Estrategias de Adaptación en el Formativo (Agro-Alfarero Temprano) de la Puna Meridional 
Argentina. Un Caso de Estudio: Antofagasta de la Sierra (Pcia. de Catamarca, R.A.). Tesis para optar al grado de Doctor en Ciencias Naturales, Facultad de Ciencias Naturales, Universidad de La Plata, La Plata.

Olivera, D.E. 1998. Cazadores y pastores tempranos de la Puna Argentina. Etnologiska Studier 42:153-180.

Olivera, D.E., P. Tchilinguirian y M.J. De Aguirre 2006. Cultural and environmental evolution in the meridional sector of the Puna of Atacama during the Holocene. Proceedings of XIVth UISPP Congress. Change in the Andes: Origins of Social Complexity, Pastoralism and Agriculture, pp. 7-15. BAR International Series 1524, Oxford, England.

Olivera, D.E., A.S. Vidal y L.G. Grana 2003. El sitio Cueva Cacao 1A: hallazgos, espacio y proceso de complejidad en la Puna Meridional (ca. 3000 a.p.). Relaciones de la Sociedad Argentina de Antropología 28:257-270.

Panter-Brick, C., R.H. Layton y P. Rowley-Conwy 2001. Lines of enquiry. En Hunter-Gatherers: An Interdisciplinary Perspective, editado por C. Panter-Brick, R. Layton y P. Rowley-Conwy, pp. 1-11. Cambridge University Press, Cambridge.

Pintar, E.S. 1996. Prehistoric Holocene Adaptations to the Salt Puna of Northwest Argentina. Ph.D. Dissertation, Southern Methodist University, Texas.

- - - 2004. Cueva Salamanca 1: ocupaciones altitermales en la Puna Sur (Catamarca). Relaciones de la Sociedad Argentina de Antropología 29:357-366.

Price, T.D. y B. Gebauer (eds.) 1995. Last Hunters First Farmers. New Perspectives on the Prehistoric Transition to Agriculture. School of American Research Press, Santa Fe, New Mexico.

Rafferty, J. 1985. The archaeological record on sedentariness: Recognition, development, and implications. Advances in Archaeological Method and Theory 8:113-156.

Reigadas, M.C. 2000-2002. Innovación tecnológica como factor de cambio en las estrategias económicas. La domesticación animal. Cuadernos del Instituto Nacional de Antropología y Pensamiento Latinoamericano 19:573-597.

- - - 2008. Explotación de recursos animales y producción textil durante el Holoceno en Antofagasta de la Sierra. Estudios Atacameños 35:35-48.

Rodríguez, M.F. 1999. Arqueobotánica de Quebrada Seca 3 (Puna Meridional Argentina): especies vegetales utilizadas en la confección de artefactos durante el Arcaico. Relaciones de la Sociedad Argentina de Antropología XXIV:159-185.

- - - 2004. Cambios en el uso de los recursos vegetales durante los distintos momentos del Holoceno en la Puna Meridional Argentina. Chungara Revista de Antropología Chilena 36 número especial, Tomo I, pp. 403-413.

Rodríguez, M.F. y Z.E. Rúgolo de Agrasar 1999. Deyeuxia eminens (Poaceae: Agrostidae) en un sitio arqueológico de la Puna Meridional Argentina (Provincia de Catamarca). Darwiniana. 37:229-242.
Rowley-Conwy, P. 2001. Time, change and the archaeology of hunter-gatherers: how original is the "Original Affluent Society". En Hunter-Gatherers: An Interdisciplinary Perspective, editado por C. Panter-Brick, R. Layton y P. Rowley-Conwy, pp. 39-72. Cambridge University Press, Cambridge.

Smith, B.D. 2001. Low-level food production. Journal of Archaeological Research 9:1-43.

Stiles, D. 2001. Hunter-gatherer studies: The importance of context. African Study Monographs 26:41-65.

Svelebil, M. 2009. Choice and necessity. A view from the Old World on the origins and dispersal of agriculture. Current Anthropology 50:699-702.

Tchilinguirian, P. y D.E. Olivera 2009. Paleoambientes y geoarqueología: Sitios Corral Grande y Arroyo Las Pitas. Antofagasta de la Sierra (Prov. de Catamarca, Puna Meridional Argentina). En Arqueometría Latinoamericana $2^{\circ}$ Congreso Argentino y $1^{\circ}$ Latinoamericano, editado por O. Palacios, C. Vázquez, T. Palacios y E. Cabanillas, pp. 544-551. CONEA y Universidad de San Martín, 2, Buenos Aires.

Troll, C. 1958. Las Culturas Superiores Andinas y el Medio Geográfico. Publicaciones del Instituto de Geografía, Facultad de Letras, Universidad Nacional Mayor de San Marcos, Lima.

Whittle, A. y V. Cummings (eds.). 2007. Going over: The Mesolithic-Neolithic transition in North-West Europe. Proceedings of the British Academy, Volume 144. British Academy. Oxford University Press, Oxford.

Yacobaccio, H. 1994. Biomasa animal y consumo en el PleistocenoHoloceno Surandino. Arqueología 4:43-63.

- - - 1998. The evolution of South Andean hunter-gatherers. International Union of Prehistoric and Protohistoric Sciences. Proceedings of the XIII Congress, pp. 389-394. ABACO Edizioni, Forli.

- - - 2000. Inhumación de una cabeza aislada en la Puna Argentina. Estudios Sociales del NOA 4:59-72.

- - - 2001. La domesticación de camélidos en el Noroeste Argentino. En Historia Argentina Prehispánica. Vol. 1, editado por E. Berberián y A. Nielsen, pp. 7-40. Editorial Brujas, 1, Córdoba.

Yacobaccio, H., D. Elkin y D. Olivera 1994. ¿El fin de las sociedades cazadoras? El proceso de domesticación animal en los Andes Centro Sur. En Arqueología de Cazadores-Recolectores. Límites, Casos y Aperturas. Arqueología Contemporánea, Edición Especial 5:23-32, editado por J.L. Lanata y L.A. Borrero, Buenos Aires.

Yacobaccio, H., C. Madero, M. Malmierca y M. Reigadas 19971998. Caza, domesticación y pastoreo de camélidos en la Puna Argentina. Relaciones de la Sociedad Argentina de Antropología XXIII:389-421.

Yacobaccio, H. y M. Morales 2005. Mid-Holocene environment and human occupation of the Puna (Susques, Argentina). Quaternary International 132:5-14. 
